\title{
Ventilatory response to exercise in adolescents with cystic fibrosis and mild-to-moderate airway obstruction
}

\author{
Bart C Bongers ${ }^{1,2^{*}}$, Maarten S Werkman ${ }^{2,3}$, Tim Takken² and Erik H J Hulzebos ${ }^{2}$
}

\begin{abstract}
Data regarding the ventilatory response to exercise in adolescents with mild-to-moderate cystic fibrosis (CF) are equivocal. This study aimed to describe the ventilatory response during a progressive cardiopulmonary exercise test (CPET) up to maximal exertion, as well as to assess the adequacy of the ventilatory response for carbon dioxide $\left(\mathrm{CO}_{2}\right)$ exhalation. Twenty-two adolescents with CF (12 boys and 10 girls; mean \pm SD age: $14.3 \pm 1.3$ years; FEV $: 78.6 \pm 17.3 \%$ of predicted) performed a maximal CPET. For each patient, data of a sex- and age matched healthy control was included (12 boys and 10 girls; mean \pm SD age: $14.3 \pm 1.4$ years). At different relative exercise intensities of 25\%, $50 \%, 75 \%$, and $100 \%$ of peak oxygen uptake $\left(\mathrm{VO}_{2 \text { peak }}\right)$, breathing pattern, estimated ventilatory dead space ventilation (VD/NT ratio), minute ventilation (VE) to $\mathrm{CO}_{2}$ production relationship $\left(\mathrm{VE} / \mathrm{NCO}_{2}\right.$-slope), partial end-tidal $\mathrm{CO}_{2}$ tension $\left(\mathrm{P}_{\mathrm{ET}} \mathrm{CO}_{2}\right)$, and the $\mathrm{VE}$ to the work rate (VE/WR) ratio were examined. $\mathrm{VO}_{2 \text { peak }}$ was significantly reduced in CF patients $(P=0.01)$. We found no differences in breathing pattern between both groups, except for a significantly higher $V E$ at rest and a trend towards a lower VE at peak exercise in patients with CF. Significantly higher values were found for the estimated VD/NT ratio throughout the CPET in CF patients $(\mathrm{P}<0.01)$. VE $/ \mathrm{NCO}_{2}$-slope and $\mathrm{P}_{\mathrm{ET}} \mathrm{CO}_{2}$ values differed not between the two groups throughout the CPET. VE/WR ratio values were significantly higher in CF during the entire range of the CPET ( $P<0.01)$. This study found an exaggerated ventilatory response (high VE/WR ratio values), which was adequate for $\mathrm{CO}_{2}$ exhalation (normal $V E N \mathrm{CO}_{2}$-slope and $\mathrm{P}_{\mathrm{ET}} \mathrm{CO}_{2}$ values) during progressive exercise up to maximal exhaustion in CF patients with mild-to-moderate airway obstruction.
\end{abstract}

Keywords: Pulmonary physiology; Ventilation; Breathing pattern; Children

\section{Background}

Peak oxygen uptake $\left(\mathrm{VO}_{2 \text { peak }}\right)$ is reported to be limited in patients with cystic fibrosis (CF) (Bongers et al. 2012; Hjeltnes et al. 1984; Keochkerian et al. 2008; Shah et al. 1998; Wideman et al. 2009). This reduction seems to have a multifactorial cause (Selvadurai et al. 2002). Respiratory, cardiovascular, as well as peripheral muscle function are reported as potential exercise limiting mechanisms (Almajed and Lands 2012). In patients with mild to moderate pulmonary disease, non-pulmonary factors, such as low muscle mass, impaired skeletal muscle function and centrally mediated oxygen delivery, seem to predominate

\footnotetext{
*Correspondence: b.c.bongers-3@umcutrecht.nl

'Department of Epidemiology, School for Public Health and Primary Care

(CAPHRI), Maastricht University, Maastricht, The Netherlands

${ }^{2}$ Child Development \& Exercise Center, Wilhelmina Children's Hospital,

University Medical Center Utrecht, Utrecht, The Netherlands

Full list of author information is available at the end of the article
}

in limiting exercise capacity (Regnis et al. 1996; Moorcroft et al. 2005; Saynor et al. 2014). In more severe patients with $\mathrm{CF}$ (forced expiratory volume in one second $\left(\mathrm{FEV}_{1}\right)<60 \%$ of predicted), ventilatory constraints and impaired gas exchange become more important determinants.

Due to continuous airflow obstruction, as reflected by a decreased $\mathrm{FEV}_{1}$ and dynamic hyperinflation, adolescents with CF have been described to develop a rapid shallow breathing pattern at rest (Hart et al. 2002) and during exercise (Keochkerian et al. 2005). This can be accompanied with a decreased ventilatory capacity and concomitant reduced $\mathrm{VO}_{2 \text { peak }}$ (Keochkerian et al. 2008). Children and adolescents with CF with static hyperinflation at rest (residual volume to total lung capacity ratio (RV/TLC) $>30 \%$ ) seem to be more prone to a ventilatory limitation during exercise, which appears to be associated with decreased 
exercise performance (Sovtic et al. 2013; Werkman et al. 2010).

A recent study found that exercise limitation in adult patients with $\mathrm{CF}$ is multifactorial and that it was dominantly correlated with $\mathrm{FEV}_{1}$ and nutritional and inflammatory status, but also with the magnitude of the overall ventilatory response during exercise (Pastré et al. 2014). In patients with severe airway obstruction $\left(\mathrm{FEV}_{1}<50 \%\right.$ of predicted), multivariate analysis revealed the $\mathrm{FEV}_{1}$ to be a significant independent predictor of exercise capacity, whereas the ratio between minute ventilation and carbon dioxide exhalation $\left(\mathrm{VE} / \mathrm{VCO}_{2}\right.$ ratio) at peak exercise was the major determinant of exercise limitation in patients with mild-to-moderate disease $\left(\mathrm{FEV}_{1}>50 \%\right.$ of predicted) (Pastré et al. 2014). However, knowledge about the ventilatory response to exercise in adolescent patients with mild to moderate $\mathrm{CF}$ is ambiguous and inconclusive. Several studies in mild-to-moderate adolescents with $\mathrm{CF}$ describe an exaggerated ventilatory response with a rapid shallow breathing pattern at rest (Hart et al. 2002) and during exercise (Keochkerian et al. 2008). On the contrary, a recent study in adolescents with mild CF did not find any evidence for a different ventilatory response and/or rapid shallow breathing pattern during exercise (Borel et al. 2014). As the two studies demonstrating exaggerated ventilatory responses were performed in adolescents with CF with lower $\mathrm{FEV}_{1}$ values, this suggests that the ventilatory response to exercise is at least partially affected by the degree of airway obstruction.

Moreover, questions can be raised whether the adopted rapid shallow breathing pattern is beneficial as higher breathing frequencies seem to increase ventilatory dead space ventilation (VD/VT ratio), as has been reported in patients with $\mathrm{CF}$ waiting for lung transplantation (Thin et al. 2004). However, adding additional dead space volume during exercise in patients with mild CF lung disease had no influence on $\mathrm{VO}_{2 \text { peak }}$ and the duration of the exercise test, and it even increased ventilation which was attributed to an increased tidal volume with no change in respiratory rate (Dodd et al. 2006). The increased dead space volume was accompanied by higher $\mathrm{VE} / \mathrm{VCO}_{2}$ ratios during exercise (Dodd et al. 2006). This finding in patients with mild CF suggests that the ventilatory response during exercise in adolescents with CF might differ with healthy controls and that this might alter during the course of the disease. Unfortunately the recent study of Borel et al. (2014), which focussed on ventilation during the entire range of exercise, only mentioned mechanical constraints influencing ventilation and did not discuss metabolic issues related to ventilation. Moreover, they included small and unequal groups of only prepubertal children.

As lung function decreases over time in most patients with CF, exercise capacity eventually becomes limited by the lungs reaching their mechanical limits to expand (approximately at $\mathrm{FEV}_{1}$ values $\leq 60 \%$ pred) (Almajed and Lands 2012). Insight in the breathing pattern during progressive exercise in adolescents with $\mathrm{CF}$ in a broad spectrum of lung function deterioration, as well as the adequacy of this ventilatory response for carbon dioxide $\left(\mathrm{CO}_{2}\right)$ exhalation, is clinically relevant for future therapeutic interventions. Therefore, the aim of the current study was 1 ) to describe the ventilatory response during a progressive cardiopulmonary exercise test (CPET) up to maximal exertion in adolescents with mild-to-moderate $\mathrm{CF}$ and 2) to assess the adequacy of the ventilatory response for $\mathrm{CO}_{2}$ exhalation (determined from partial end-tidal carbon dioxide tension $\left(\mathrm{P}_{\mathrm{ET}} \mathrm{CO}_{2}\right)$ ) throughout the CPET in mild-to-moderate patients with CF. Our hypothesis is that adolescents with CF develop an obstructive breathing pattern, combined with a relatively large VD/VT ratio, which limit $\mathrm{CO}_{2}$ wash out.

\section{Methods \\ Participants}

Exercise data of twenty-two adolescents (12 boys and 10 girls from 12 to 17 years of age, mean \pm SD age: $14.3 \pm$ 1.3 years) with mild-to-moderate $\mathrm{CF}$ were randomly selected from the exercise database from the CF Center at the University Medical Center Utrecht. The database contained anonymous patient data of anthropometry, lung function and exercise capacity which was measured as part of usual care at the routine annual check-up. Therefore, all patients were free from acute pulmonary or gastrointestinal exacerbation at the time of testing. Testing procedures used in this study met the assumptions for standard of practice for the routine care of patients with CF. For each patient with CF, an age, sex and anthropometrically matched healthy control who performed a maximal CPET in our hospital retrospectively was selected (untrained and normal physical activity level). All participants and their guardians provided approval for inclusion of the data in research studies. After evaluation, the medical ethical committee of the University Medical Center Utrecht determined that inclusion of the data conformed to the regulations of the Dutch CF Registration and that inclusion of the data in this study met the ethical polices of the University Medical Center Utrecht, as well as the regulations of the Dutch government.

\section{Anthropometric measures}

Body mass and body height were determined using an electronic scale (Seca, Hamburg, Germany) and a stadiometer (Ulmer Stadiometer, Ulm, Germany) respectively. Body mass index (BMI) was calculated as the body mass in kilograms divided by the square of the body height in meters. Standard deviation (SD) scores were calculated 
for body height for age, body mass for age, and BMI for age using Dutch normative values (Fredriks et al. 2000). The equation of Haycock et al. (1978), validated in infants, children, and adults, was used to obtain the participants' body surface area (BSA).

\section{Spirometry and plethysmography}

In the patients with CF, spirometry and plethysmography were performed by qualified lung function analysts of the CF Center at the University Medical Center Utrecht. Since the healthy controls were not known with any disease, spirometry and plethysmography was not performed in this group. In order to prevent the potential influence of bronchial reactivity during exercise, spirometry and plethysmography were performed after bronchodilation with salbutamol $(800 \mu \mathrm{g})$. $\mathrm{FEV}_{1}$ was obtained from flow volume curves (Masterscreen, Jaeger, Würzburg, Germany). Residual volume (RV) and total lung volume (TLC) were determined in a body plethysmograph (Master Lab system, Jaeger, Würzburg, Germany). The RV was expressed as a percentage of TLC (RV/TLC ratio) as well. In order to improve comparative possibilities with the reports of other studies in CF, we used the commonly used reference values of Zapletal et al. (1987) to express lung function values as percentage of predicted values.

\section{Cardiopulmonary exercise test}

All participants completed a maximal CPET using an electronically braked cycle ergometer (Jaeger Physis, Carefusion, Houten, The Netherlands) after bronchodilation with salbutamol. After three minutes of rest measurements, cycling started at a workload of $0 \mathrm{~W}$. Then, the work rate (WR) was linearly incremented with a $15 \mathrm{~W} \cdot \mathrm{min}^{-1}$ ramp protocol (Godfrey 1974) until the patient stopped due to volitional exhaustion, despite strong verbal encouragement. The test effort was considered maximal when the participant showed objective (heart rate $(\mathrm{HR})$ at peak exercise $\left(\mathrm{HR}_{\text {peak }}\right)>180$ beats $\cdot \mathrm{min}^{-1}$ and/or a respiratory exchange ratio (RER) at peak exercise $\left(\mathrm{RER}_{\text {peak }}\right)>1.0$ ) (Armstrong and Welsman 2008) and subjective (unsteady biking, sweating, facial flushing, and clear unwillingness to continue despite encouragement) signs of maximal effort.

Throughout the CPET, participants breathed through a facemask (dead space volume 63 or $72 \mathrm{~mL}$, dependent on size) (Hans Rudolph Inc, Kansas City, MO) that was connected to a calibrated metabolic cart (Oxycon Pro, Carefusion, Houten, the Netherlands). Gas analyzers were calibrated using gases of known concentration, whereas the flow meter was calibrated using a three-liter syringe (Hans Rudolph Inc, Kansas City, MO). Expired gas passed through a flow meter and a gas analyzer connected to a computer, which calculated breath-by-breath minute ventilation (VE), oxygen uptake $\left(\mathrm{VO}_{2}\right), \mathrm{VCO}_{2}$ and RER from conventional equations. Output from the flow meter and gas analyzers were averaged over ten-second intervals and stored for further use. Relative $\mathrm{VO}_{2 \text { peak }}$ $\left(\mathrm{VO}_{2 \text { peak }} / \mathrm{kg}\right)$ was calculated by dividing $\mathrm{VO}_{2 \text { peak }}$ by body mass. HR was monitored continuously by a threelead electrocardiogram (Hewlett-Packard, Amstelveen, Netherlands) and transcutaneous $\mathrm{O}_{2}$ saturation at the index finger was measured by pulse oximetry (Nellcor 200 E, Nellcor, Breda, the Netherlands). Peak exercise parameters were defined as the highest values achieved within the last 30 seconds prior to exhaustion.

\section{Data analysis}

The ventilatory threshold was defined as the point at which the ventilatory equivalent for oxygen and the partial end-tidal oxygen tension reached a minimum and thereafter began to rise in a consistent manner, coinciding with an unchanged ventilatory equivalent for carbon dioxide and a peak in the $\mathrm{P}_{\mathrm{ET}} \mathrm{CO}_{2}$ course (American Thoracic Society, American College of Chest Physicians 2003; Ohuchi et al. 1996). When this ventilatory equivalents

\section{Table 1 Participant characteristics}

\begin{tabular}{|c|c|c|c|}
\hline & $\begin{array}{l}\text { Healthy } \\
(n=22)\end{array}$ & $\begin{array}{c}C F \\
(n=22)\end{array}$ & $P$-value \\
\hline Sex (boy/girl) & $12 / 10$ & $12 / 10$ & $N A$ \\
\hline Age (years) & $14.3 \pm 1.4$ & $14.3 \pm 1.3$ & 0.99 \\
\hline $\begin{array}{l}\text { CF mutation class } \\
(\text { (I/I//V/ } / \text { unknown })^{\mathrm{a}}\end{array}$ & NA & $9 / 27 / 1 / 6$ & $N A$ \\
\hline $\begin{array}{l}\text { PA colonization (never/free } \\
\text { of infection/intermittent/chronic) }\end{array}$ & NA & $6 / 1 / 6 / 9$ & $N A$ \\
\hline Body height (m) & $1.67 \pm 0.10$ & $1.65 \pm 0.09$ & 0.61 \\
\hline Body height for age SDS ${ }^{c}$ & $0.17 \pm 0.86$ & $-0.18 \pm 0.99$ & 0.24 \\
\hline Body mass (kg) & $53.9 \pm 12.2$ & $50.2 \pm 7.2$ & 0.31 \\
\hline Body mass for age $\mathrm{SDS}^{\mathrm{C}}$ & $0.02 \pm 0.83$ & $-0.37 \pm 0.64$ & 0.13 \\
\hline BMI $\left(\mathrm{kg} \cdot \mathrm{m}^{-2}\right)$ & $19.1 \pm 2.6$ & $18.5 \pm 2.0$ & 0.51 \\
\hline BMl for age SDSC & $-0.09 \pm 0.80$ & $-0.34 \pm 0.85$ & 0.37 \\
\hline $\mathrm{BSA}\left(\mathrm{m}^{2}\right)$ & $1.57 \pm 0.22$ & $1.54 \pm 0.14$ & 0.72 \\
\hline $\mathrm{FEV}_{1}(\mathrm{~L})$ & NA & $2.52 \pm 0.67$ & $N A$ \\
\hline $\mathrm{FEV}_{1}(\% \text { pred })^{\mathrm{d}}$ & NA & $78.6 \pm 17.3$ & NA \\
\hline RV/TLC (\%) & $N A$ & $33.5 \pm 9.3$ & $N A$ \\
\hline $\mathrm{VO}_{2 \text { peak }} / \mathrm{kg}\left(\mathrm{mL} \cdot \mathrm{kg}^{-1} \cdot \mathrm{min}^{-1}\right)$ & $49.1 \pm 7.2$ & $42.4 \pm 8.7$ & $<0.01^{* *}$ \\
\hline
\end{tabular}

Values are presented as mean $\pm \mathrm{SD}$.

Abbreviations: $B M I$ body mass index, $B S A$ body surface area, $C F$ cystic fibrosis, CFTR cystic fibrosis transmembrane conductance regulator, FEV forced expiratory volume in one second, NA not applicable, NS not statistically significant, RV/TLC residual volume to total lung capacity ratio, SDS standard deviation score.

**P $<0.01$.

${ }^{\mathrm{a}}$ Based on the classification of CFTR alleles used by Green et al. (2010).

${ }^{\mathrm{b}}$ Based on the criteria of Lee et al. (2003).

'Reference values of Fredriks et al. (2000).

deference values of Zapletal et al. (1987). 
method appeared to provide uncertain results for a participant's ventilatory threshold $(\mathrm{n}=4,18 \%$, in the CF patients, $\mathrm{n}=0$ in the healthy controls), the point at which the linear slope of the relation between the $\mathrm{VCO}_{2}$ and $\mathrm{VO}_{2}$ changed was taken as the ventilatory threshold, according to the Vslope method (Beaver et al. 1986). The ventilatory threshold $\left(\mathrm{VO}_{2}\right)$ was expressed as an absolute value, relative value ( $\mathrm{VO}_{2}$ normalized for body mass) and as a percentage of the attained $\mathrm{VO}_{2 \text { peak }}$. The estimated $\mathrm{VD} / \mathrm{VT}$ ratio was calculated by using the $\mathrm{P}_{\mathrm{ET}} \mathrm{CO}_{2}$. The graphical presentation of $\mathrm{VE}$ as a function of $\mathrm{VCO}_{2}$ during the progressive CPET was used to determine the point at which VE increased out of proportion to $\mathrm{VCO}_{2}$, the respiratory compensation point.
Next to resting values, tidal volume, breathing frequency, $\mathrm{VE}, \mathrm{VD} / \mathrm{VT}$ ratio, and $\mathrm{P}_{\mathrm{ET}} \mathrm{CO}_{2}$ were determined as an average of 30 seconds at different exercise intensities of $25 \%, 50 \%, 75 \%$ and $100 \%$ of $\mathrm{VO}_{2 \text { peak. }}$. Both $\mathrm{VE}$ and tidal volume were adjusted for body mass as well. To allow for fair comparison, resting $\mathrm{VO}_{2}$ was subtracted from $\mathrm{VO}_{2 \text { peak. }}$. Subsequently, $25 \%, 50 \%, 75 \%$ and $100 \%$ of this delta $\mathrm{VO}_{2}$ was calculated and summed with the resting $\mathrm{VO}_{2}$ for each participant (CF patients and healthy controls). Furthermore, we calculated the $\mathrm{VE}$ to $\mathrm{VO}_{2}$ relationship (VE/ $/ \mathrm{VO}_{2}$-slope) and the $\mathrm{VE}$ to $\mathrm{VCO}_{2}$ relationship (VE/ $/ \mathrm{VCO}_{2}$-slope) at the same different exercise intensities by linear regression of the exercise data up to $25 \%, 50 \%$, $75 \%$, and $100 \%$ of $\mathrm{VO}_{2 \text { peak }}$ using the least squares

Table 2 Exercise performance in the healthy adolescents and adolescents with CF

\begin{tabular}{|c|c|c|c|}
\hline & Healthy $(n=22)$ & $C F(n=22)$ & $P$-value \\
\hline \multicolumn{4}{|l|}{ Maximal values } \\
\hline$H R_{\text {peak }}\left(\right.$ beats $\cdot \min ^{-1}$ ) & $192 \pm 7$ & $186 \pm 8$ & $0.02^{*}$ \\
\hline$R E R_{\text {peak }}$ & $1.15 \pm 0.08$ & $1.19 \pm 0.09$ & 0.16 \\
\hline$W R_{\text {peak }}(W)$ & $222 \pm 62$ & $164 \pm 32$ & $<0.01^{* *}$ \\
\hline$W R_{\text {peak }} / \mathrm{kg}\left(\mathrm{W} \cdot \mathrm{kg}^{-1}\right)$ & $4.2 \pm 0.6$ & $3.3 \pm 0.5$ & $<0.001^{* * *}$ \\
\hline $\mathrm{VO}_{2 \text { peak }}\left(\mathrm{mL} \cdot \mathrm{min}^{-1}\right)$ & $2638 \pm 685$ & $2126 \pm 516$ & $0.01^{*}$ \\
\hline $\mathrm{VO}_{2 \text { peak }} / \mathrm{kg}\left(\mathrm{mL} \cdot \mathrm{kg}^{-1} \cdot \mathrm{min}^{-1}\right)$ & $49.1 \pm 7.2$ & $42.4 \pm 8.7$ & $<0.01^{* *}$ \\
\hline $\mathrm{VO}_{2 \text { peak }} / \mathrm{BSA}\left(\mathrm{mL} \cdot \mathrm{m}^{2} \cdot \mathrm{min}^{-1}\right)$ & $1667 \pm 259$ & $1378 \pm 274$ & $<0.01^{* *}$ \\
\hline $\mathrm{VCO}_{2 \text { peak }}\left(\mathrm{mL} \cdot \mathrm{min}^{-1}\right)$ & $2963 \pm 871$ & $2409 \pm 540$ & $0.03^{*}$ \\
\hline $\mathrm{VCO}_{2 \text { peak }} / \mathrm{kg}\left(\mathrm{mL} \cdot \mathrm{kg}^{-1} \cdot \mathrm{min}^{-1}\right)$ & $54.9 \pm 8.9$ & $48.1 \pm 9.7$ & $0.02^{*}$ \\
\hline$V E @ V O_{2 \text { peak }}\left(L \cdot \min ^{-1}\right)$ & $89.5 \pm 27.2$ & $75.8 \pm 18.8$ & 0.08 \\
\hline $\mathrm{VE} / \mathrm{kg} @ \mathrm{VO}_{2 \text { peak }}\left(\mathrm{L} \cdot \mathrm{kg}^{-1} \cdot \mathrm{min}^{-1}\right)$ & $1.7 \pm 0.3$ & $1.5 \pm 0.3$ & $0.04^{*}$ \\
\hline Absolute tidal volume @ VO 2peak $(\mathrm{mL})$ & $1736 \pm 339$ & $1616 \pm 373$ & 0.32 \\
\hline Relative tidal volume @ VO 2 peak $\left(\mathrm{mL} \cdot \mathrm{kg}^{-1}\right)$ & $32.7 \pm 4.8$ & $32.2 \pm 6.4$ & 0.98 \\
\hline Breathing frequency@ $\mathrm{VO}_{2 \text { peak }}\left(\right.$ breaths·min ${ }^{-1}$ ) & $51 \pm 9$ & $48 \pm 9$ & 0.25 \\
\hline Estimated VDNT ratio @ VO 2 peak $(\%)$ & $17 \pm 2$ & $21 \pm 4$ & $<0.001^{* * *}$ \\
\hline $\mathrm{P}_{\mathrm{ET}} \mathrm{CO}_{2} @ \mathrm{VO}_{2 \text { peak }}(\mathrm{mmHg})$ & $36.3 \pm 3.2$ & $38.2 \pm 3.7$ & 0.10 \\
\hline VE/WR ratio @ VO 2 peak $\left(\mathrm{mL} \cdot \mathrm{min}^{-1} \cdot \mathrm{W}^{-1}\right)$ & $399 \pm 57$ & $476 \pm 71$ & $<0.001^{* * *}$ \\
\hline \multicolumn{4}{|l|}{ Submaximal values } \\
\hline Absolute ventilatory threshold $\left(\mathrm{mL} \cdot \mathrm{min}^{-1}\right)$ & $1439 \pm 381$ & $1216 \pm 253$ & 0.07 \\
\hline Relative ventilatory threshold $\left(\mathrm{mL} \cdot \mathrm{kg}^{-1} \cdot \mathrm{min}^{-1}\right)$ & $27.1 \pm 6.1$ & $24.4 \pm 5.1$ & 0.13 \\
\hline Ventilatory threshold $\left(\% \mathrm{VO}_{2 \text { peak }}\right)$ & $55 \pm 9$ & $58 \pm 9$ & 0.32 \\
\hline $\mathrm{P}_{\mathrm{ET}} \mathrm{CO}_{2} @$ rest $(\mathrm{mmHg})$ & $31.8 \pm 2.4$ & $33.5 \pm 3.2$ & $0.03^{*}$ \\
\hline $\mathrm{P}_{\mathrm{ET}} \mathrm{CO}_{2} @$ the ventilatory threshold $(\mathrm{mmHg})$ & $39.3 \pm 3.6$ & $40.0 \pm 2.6$ & 0.50 \\
\hline VENO $\mathrm{N}_{2}$-slope up to the ventilatory threshold & $20.5 \pm 3.2$ & $23.7 \pm 5.1$ & $0.02^{*}$ \\
\hline VEN $\mathrm{CCO}_{2}$-slope up to the respiratory compensation point & $26.6 \pm 2.8$ & $27.1 \pm 2.9$ & 0.60 \\
\hline
\end{tabular}

Values are presented as mean $\pm \mathrm{SD}$.

Abbreviations: $B S A$ body surface area, $C F$ cystic fibrosis, $H R_{\text {peak }}$ peak heart rate, $N S$ not statistically significant, $P_{E T} C_{2}$ partial end-tidal carbon dioxide tension, $R E R_{\text {peak }}$ peak respiratory exchange ratio, $V C O_{2 p e a k}$ peak carbon dioxide output, $V C O_{2 p e a k} / \mathrm{kg}$ peak carbon dioxide output normalized for body mass, $V D / V T$ ratio physiological dead space ventilation, $V E$ minute ventilation, $V E / k g$ minute ventilation normalized for body mass, $V E / V C O_{2}-s l o p e$ slope of the relationship between minute ventilation and carbon dioxide output, $V E / V_{2}$-slope slope of the relationship between minute ventilation and oxygen uptake, $V E / W R$ minute ventilation to work rate ratio, $V O_{2 p e a k}$ peak oxygen uptake, $V O_{2 p e a k} / \mathrm{kg}$ peak oxygen uptake normalized for body mass, $W R_{\text {peak }}$ peak work rate, $W R_{\text {peak }} / \mathrm{kg}$ peak work rate normalized for body mass.

${ }^{*} P<0.05 ;{ }^{* *} P<0.01 ;{ }^{* * *} P<0.001$. 
approach. We examined the participants' response of the VE to the WR (VE/WR ratio) at similar intensities. Data from the first minute of exercise were excluded since the breathing pattern during the first minute of exercise frequently appears to be unstable.

\section{Statistical analysis}

The Statistical Package for the Social Sciences (SPSS, version 15.0; SPSS Inc., Chicago, IL) was used for the dataanalysis. Shapiro-Wilk tests for normality were performed in order to evaluate the data distribution of each variable. Differences between adolescents with CF and their healthy counterparts in anthropometry and in exercise data at different exercise intensities were examined with MannWhitney U tests. Data are presented as mean values \pm SD. A P-value $<0.05$ was considered as statistically significant.

\section{Results}

Anthropometric data for the patients with CF and the healthy controls are presented in Table 1, with no significant anthropometric between-group differences. Lung function characteristics of the adolescents with CF are also shown in Table 1. Patients had mild-to-moderate airway obstruction (mean $\mathrm{FEV}_{1}$ expressed as a percentage of predicted of $79 \pm 17 \%$ ) and a mild-to-moderate degree of static hyperinflation (mean RV/TLC ratio of $34 \pm 9 \%$ ). More specifically, 14 patients ( 5 boys and 9 girls) had an absolute RV/TLC ratio greater than $30 \%$, which suggests static hyperinflation (Eid et al. 2000).

All participants performed a maximal effort during the CPET (mean test duration of $623 \pm 139$ and $659 \pm$
194 seconds for the CF patients and healthy controls respectively), and the results are presented in Table 2. Compared with the healthy controls, adolescents with CF attained significantly lower values for $H_{\text {peak }}$, peak WR $\left(\mathrm{WR}_{\text {peak }}\right.$ ), WR $\mathrm{WRak}_{\text {peak }} / \mathrm{kg}, \mathrm{VO}_{2 \text { peak }}, \mathrm{VO}_{2 \text { peak }} / \mathrm{kg}, \mathrm{VO}_{\text {2peak }} / \mathrm{m}^{2}$ (normalized for BSA), peak $\mathrm{VCO}_{2}\left(\mathrm{VCO}_{2 \text { peak }}\right), \mathrm{VCO}_{2 \text { peak }} / \mathrm{kg}$, and peak VE $\left(\mathrm{VE}_{\text {peak }}\right)$ normalized for body mass $\left(\mathrm{VE}_{\text {peak }} / \mathrm{kg}\right)$, whereas they attained significantly higher values for the estimated VD/VT ratio at peak exercise, the $\mathrm{VE} / \mathrm{VO}_{2}$ slope up to the ventilatory threshold, $\mathrm{P}_{\mathrm{ET}} \mathrm{CO}_{2}$ at rest, and the VE/WR ratio at peak exercise.

Breathing pattern components, tidal volume and breathing frequency, adopted during exercise did not differ significantly between patients with CF and healthy adolescents, except for a significantly higher breathing frequency at rest $\left(19 \pm 3\right.$ versus $22 \pm 5$ breaths $\left.\cdot \mathrm{min}^{-1} ; \mathrm{P}=0.02\right)$ and a trend for lower absolute tidal volume values at or near maximal exercise in patients with CF $(1.74 \pm 0.34$ versus $1.62 \pm$ $0.37 \mathrm{~L} ; \mathrm{P}=0.32$ ). Consequently, VE at rest was significantly higher $\left(11.5 \pm 2.1\right.$ versus $\left.13.8 \pm 3.4 \mathrm{~L} \cdot \mathrm{min}^{-1} ; \mathrm{P}=0.02\right)$, whereas $\mathrm{VE}_{\text {peak }}\left(75.8 \pm 18.8\right.$ versus $89.5 \pm 27.2 \mathrm{Lmin}^{-1}$; $\mathrm{P}=0.08)$ tended to be lower in patients with CF. VE normalized for body mass (VE $/ \mathrm{kg}$ ) was significantly higher at rest $\left(0.2 \pm 0.05\right.$ versus $\left.0.3 \pm 0.06 \mathrm{~L} \cdot \mathrm{kg}^{-1} \cdot \mathrm{min}^{-1} ; \mathrm{P}<0.01\right)$ and at $25 \%$ of $\mathrm{VO}_{\text {2peak }}\left(0.4 \pm 0.07\right.$ versus $0.5 \pm 0.08 \mathrm{~L} \cdot \mathrm{kg}^{-1} \cdot \mathrm{min}^{-1}$; $\mathrm{P}=0.03$ ) in the patients with CF. Values for breathing frequency divided by the tidal volume (rapid shallow breathing index) tended to be higher in patients with $\mathrm{CF}$ at rest ( $32 \pm 13$ versus $38 \pm 13 ; \mathrm{P}=0.14$ ) and at $25 \%$ of $\mathrm{VO}_{2 \text { peak }}$ ( $27 \pm 10$ versus $32 \pm 15 ; \mathrm{P}=0.31)$. Furthermore, estimated VD/VT ratio values were significantly higher during all

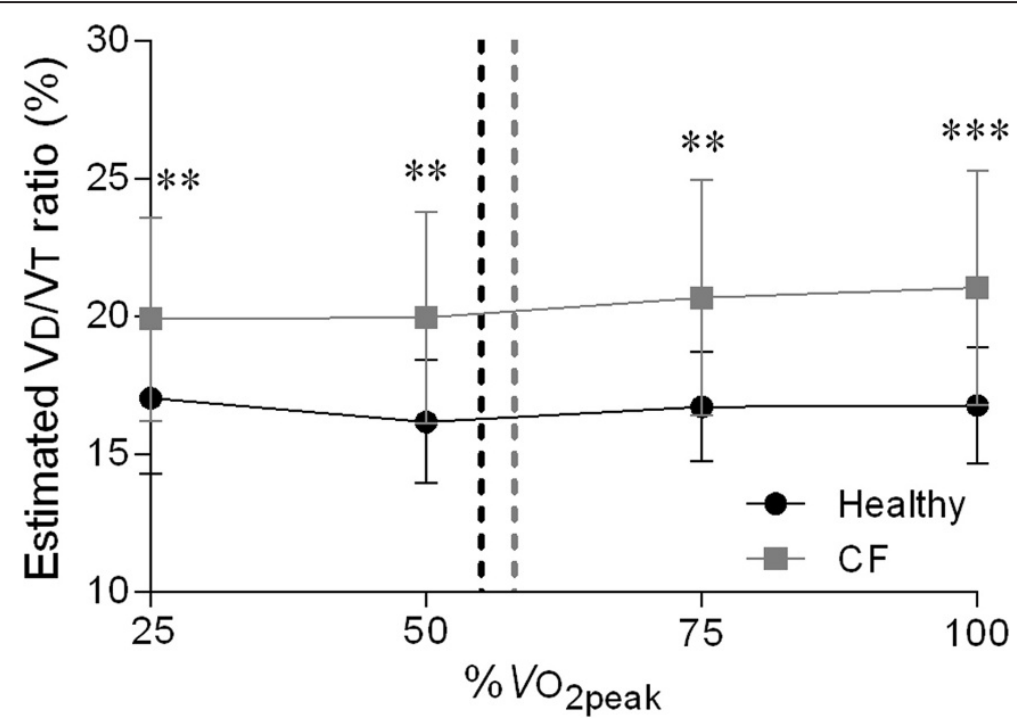

Figure 1 Changes in the estimated VD/VT ratio during exercise at similar percentages of $\mathrm{VO}_{2 \text { peak }}$ in the healthy adolescents and the adolescents with CF. Dashed lines correspond to the ventilatory threshold in both groups. Abbreviations: $C F=c y s t i c$ fibrosis; VDNT ratio $=$ physiological dead space ventilation; $\mathrm{VO}_{2 \text { peak }}=$ peak oxygen uptake. ${ }^{* *} P<0.01 ;{ }^{* *} P<0.001$. 

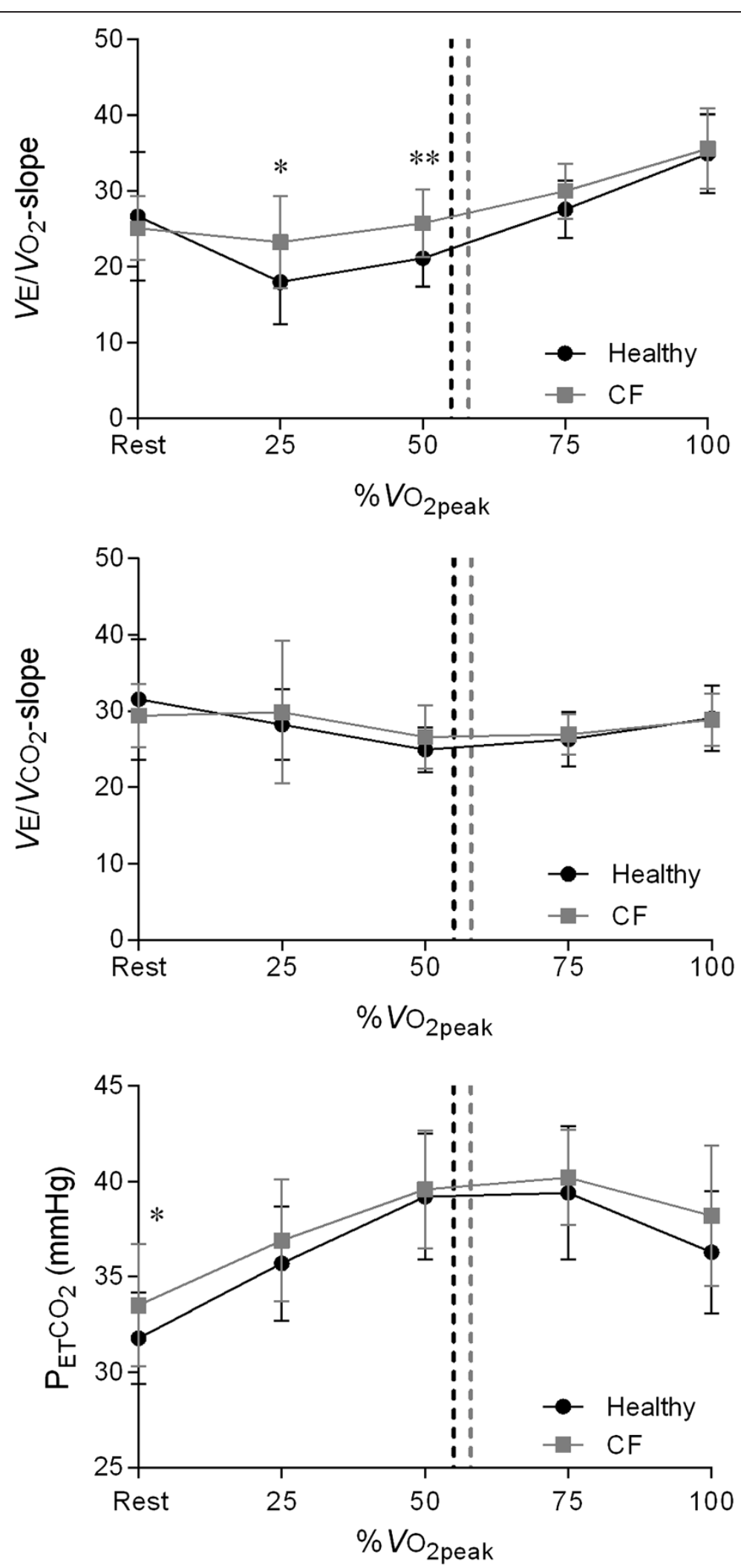

Figure 2 (See legend on next page.) 
exercise intensities in patients with CF (see Figure $1, \mathrm{P}<0.01$, $\mathrm{P}<0.01, \mathrm{P}<0.01$, and $\mathrm{P}<0.001$ at $25 \%, 50 \%, 75 \%$, and $100 \%$ of $\mathrm{VO}_{2 \text { peak }}$ respectively).

Figure 2 shows significantly higher $\mathrm{VE} / \mathrm{VO}_{2}$-slope values at $25 \%(\mathrm{P}=0.01)$ and $50 \%(\mathrm{P}<0.01)$ of $\mathrm{VO}_{2 \text { peak }}$ in patients with $\mathrm{CF}$, whereas $\mathrm{VE} / \mathrm{VCO}_{2}$-slope values differed not significantly between the two groups throughout the entire range of the CPET. Furthermore, Figure 2 demonstrates that, except for resting values $(\mathrm{P}=0.03)$, $\mathrm{P}_{\mathrm{ET}} \mathrm{CO}_{2}$ values differed not significantly between the two groups during the CPET.

Figure 3 represents the RER at rest and throughout progressive exercise in order to elucidate the higher VE/ $\mathrm{VO}_{2}$ ratios during sub-maximal exercise. At rest and during sub-maximal exercise, patients with $\mathrm{CF}$ attained significantly higher RER values $(\mathrm{P}<0.001, \mathrm{P}<0.001, \mathrm{P}<0.001$, $\mathrm{P}<0.01$, and $\mathrm{P}=0.26$ at rest, $25 \%, 50 \%, 75 \%$, and $100 \%$ of $\mathrm{VO}_{2 \text { peak }}$ respectively). The $\mathrm{VE} / \mathrm{WR}$ ratio depicted in Figure 4 was significantly higher in $\mathrm{CF}$ during the entire range of the CPET $(\mathrm{P}<0.01, \mathrm{P}<0.001, \mathrm{P}<0.001$, and $\mathrm{P}<0.001$ at $25 \%, 50 \%, 75 \%$, and $100 \%$ of $\mathrm{VO}_{2 \text { peak }}$ respectively).

\section{Discussion}

The present study aimed to 1) describe the ventilatory response during a progressive CPET and 2) assess the adequacy of the ventilatory response for $\mathrm{CO}_{2}$ exhalation during exercise in mild-moderate adolescents with $\mathrm{CF}$. First, we found an exaggerated ventilatory response during exercise. Second, this ventilatory response to exercise seems to be adequate for $\mathrm{CO}_{2}$ exhalation in patients with mild-to-moderate CF. The latter is illustrated by a similar course of the $\mathrm{VE} / \mathrm{VCO}_{2}$-slope throughout exercise, higher RER values during sub-maximal exercise, and the ability to maintain $\mathrm{P}_{\mathrm{ET}} \mathrm{CO}_{2}$ values within normal limits throughout the entire range of the CPET.

The basic physiological factors that determine and modify the ventilatory response to exercise are: 1) $\mathrm{CO}_{2}$ output of the exercising muscles, 2) the arterial $\mathrm{CO}_{2}$ setpoint, 3) the VD/VT ratio, and 4) the change in the arterial pressure of $\mathrm{CO}_{2}\left(\mathrm{PaCO}_{2}\right)$ during exercise (Wasserman et al. 1996). Several of these concepts are addressed to in this study. First, muscular $\mathrm{CO}_{2}$ output during (sub-)maximal exercise seems to be increased in patients with $\mathrm{CF}$ (Bongers et al. 2012; Hebestreit et al. 2005; Nguyen et al. 2014), which is illustrated in the current study by a higher RER. The higher RER in patients with CF is suggested to reflect a higher reliance on glucose oxidation to meet energy demands during exercise (Hebestreit et al. 2005; Nguyen et al. 2014). Altered substrate utilization in CF (de Meer et al. 1995; Moser et al. 2000; Selvadurai et al. 2003) might explain the increased RER at rest and for

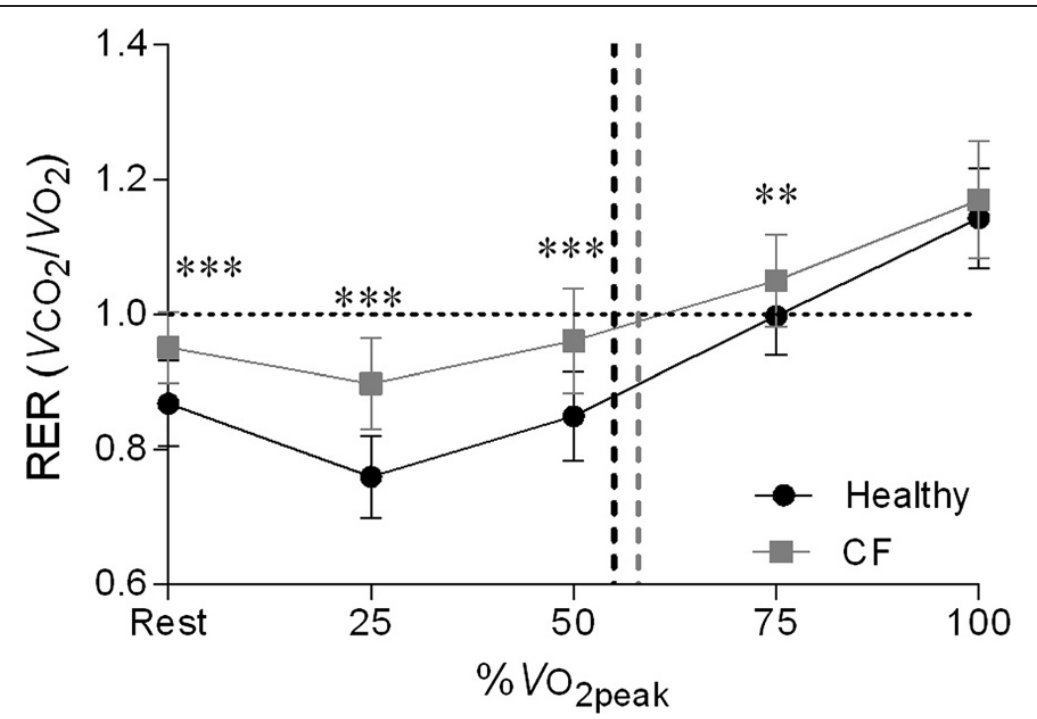

Figure 3 RER during exercise at similar percentages of $\mathbf{V O}_{2 \text { peak }}$ in healthy adolescents and patients with $\mathbf{C F}$. Vertical dashed lines

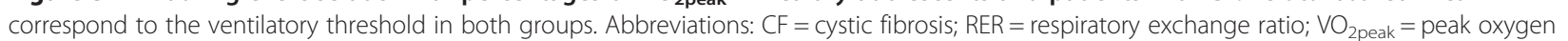
uptake. ${ }^{* *} P<0.01 ;{ }^{* * *} P<0.001$. 


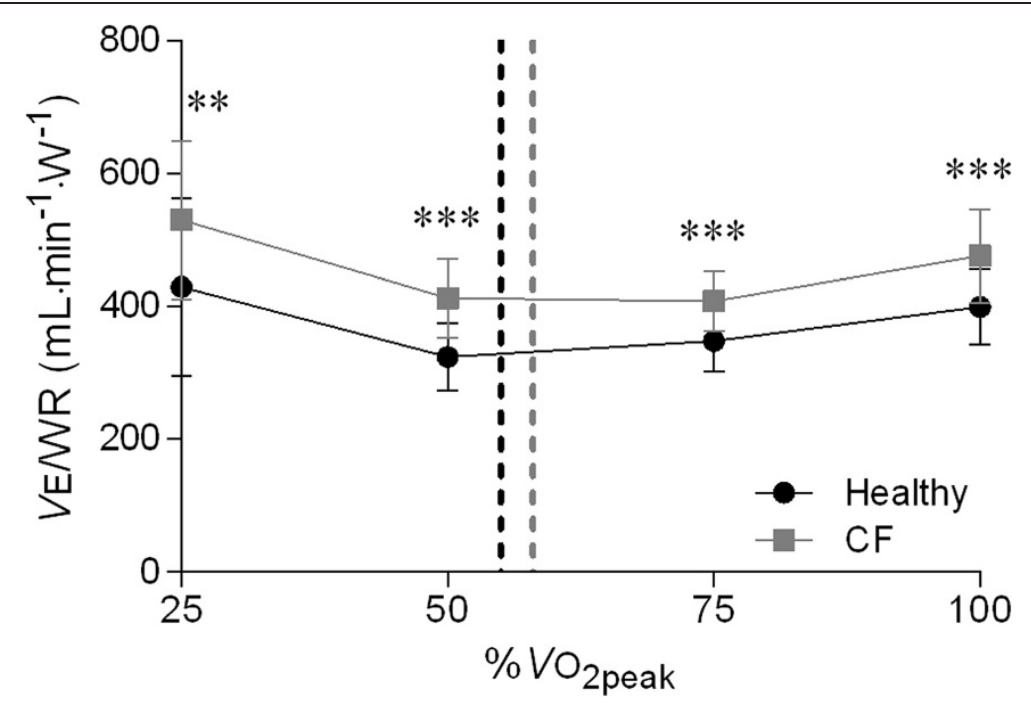

Figure 4 Changes in the VE/WR ratio during exercise at similar percentages of $\mathrm{VO}_{2 \text { peak }}$ in healthy adolescents and patients with $\mathrm{CF}$. Dashed lines correspond to the ventilatory threshold in both groups. Abbreviations: $C F=$ cystic fibrosis; VE/WR $=$ minute ventilation to work rate ratio; $V_{2} O_{2 \text { peak }}=$ peak oxygen uptake. ${ }^{* *} P<0.01 ;{ }^{* *} P<0.001$.

the lower exercise intensities. In addition, slowed $\mathrm{VO}_{2}$ kinetics during exercise and recovery in patients with CF might also be a possible explanation for an increased RER during sub-maximal exercise (Kusenbach et al. 1999; Massin et al. 2000; Pouliou et al. 2001; Hebestreit et al. 2005; Stevens et al. 2009; Saynor et al. 2014). This results in a greater dependency on glycolytic energy systems at lower exercise intensities resulting in an increased $\mathrm{VCO}_{2}$. Higher aerobic or anaerobic glycolytic energy expenditure during exercise increases ventilation as supported by a study in patients with familial mitochondrial myopathy (Heinicke et al. 2011). The current study showed an exaggerated $\mathrm{VE}$ relative to metabolic rate, indicated by high $\mathrm{VE} / \mathrm{VO}_{2}$-slope values and $\mathrm{VE} /$ WR ratios, as well as an elevated RER, with no apparent signs of pulmonary insufficiency.

Second, the VD/VT was significantly higher at all exercise intensities in patients with CF, which seems to be exaggerated with disease progression (post-hoc analysis, data not shown). High VD/VT values during exercise have previously been reported in patients with CF (Cerny et al. 1982; Coates et al. 1988; Thin et al. 2004; Wilkens et al. 2010). This, in combination with the trend of higher $\mathrm{P}_{\mathrm{ET}} \mathrm{CO}_{2}$ in patients with $\mathrm{CF}$, indicates an abnormal alveolar dead space ventilation (Wilkens et al. 2010), which might explain the relatively high VE values at rest and during sub-maximal exercise in patients with CF. Unfortunately, the exaggerated ventilatory response we found and the shift from oxidative to glycolytic energy metabolism, as shown by the attenuation of the RER slope at exercise intensities above $50 \%$ of $\mathrm{VO}_{2 \text { peak }}$ when compared to healthy controls, seems not to be able to totally compensate the limited exercise capacity in patients with $\mathrm{CF}$ (significantly reduced $\mathrm{VO}_{2 \text { peak }} / \mathrm{kg}$ and $\mathrm{WR}_{\text {peak }} / \mathrm{kg}$ ). Our results are in agreement with the study of Borel et al. (2014) who found no effect of mild CF on breathing pattern and breathing strategy during an incremental CPET. Although breathing pattern and breathing strategy of adolescents with CF were comparable with healthy controls, most studies still report a reduced exercise capacity in adolescents with CF (Almajed and Lands 2012; Rand and Prasad 2012; Saynor et al. 2014). Saynor et al. (2014) recently suggested that centrally mediated oxygen delivery might be the principally limiting the aerobic function of pediatric CF patients with mild-tomoderate airway obstruction during ramp incremental cycling exercise. However, based on the results of the study of Keochkerian et al. (2008) on the ventilatory response in children with $\mathrm{CF}$, one would still expect that $\mathrm{CF}$ could alter the ventilatory response during a progressive CPET. The current study demonstrated no significant effect of $\mathrm{CF}$ on the ventilatory response for $\mathrm{CO}_{2}$ exhalation (VE/ $\mathrm{VCO}_{2}$-slope and $\mathrm{P}_{\mathrm{ET}} \mathrm{CO}_{2}$ ) to exercise in patients with $\mathrm{CF}$ with mild-to-moderate airway obstruction.

As described above, we found higher values for RER, $\mathrm{VE} / \mathrm{WR}$, and $\mathrm{VE} / \mathrm{VO}_{2}$-slope values during sub-maximal exercise. These results suggest a higher ventilatory demand rather than a higher ventilatory response during sub-maximal exercise in patients with mild CF. An explanation for the absence of an impact of CF on the ventilatory response to exercise is the mild-to-moderate severity of the lung disease in our population. Keochkerian et al. (2008) reported that the more severe the airway obstruction, the more rapid and shallow the breathing pattern.

The current study has some limitations. Firstly, by categorizing exercise intensity by $\% \mathrm{VO}_{2 \text { peak }}$, there is no 
standardization of exercise intensity relative to the ventilatory response for each participant. However, standardizing for exercise intensity relative to $\mathrm{VO}_{2}\left(\% \mathrm{VO}_{2 \text { peak }}\right)$ was also done by other studies (Borel et al. 2014; Keochkerian et al. 2008). Since the ventilatory threshold occurred at a similar percentage of $\mathrm{VO}_{2 \text { peak }}$ in the pediatric CF patients and the healthy controls ( $58 \pm 9 \%$ versus $55 \pm 9 \% ; \mathrm{P}=0.32$ ), we believe that we did compare groups within the same physiological exercise intensity domain. Secondly, the sample size was relatively small and included mainly patients with $\mathrm{CF}$ with mild to moderate airflow obstruction. For this reason, these findings cannot be generalized to patients with severe airflow obstruction. Nevertheless, the current study sample is representative for the CF population in a tertiary CF Center. Thirdly, the estimated VD/VT ratio cannot be accurately predicted from the $\mathrm{P}_{\mathrm{ET}} \mathrm{CO}_{2}$ in patients with an increased VD/VT ratio due to lung disease (Wasserman et al. 2005), so caution must be taken with the interpretation of these results. Fourth, unfortunately we were not able to correct $\mathrm{VO}_{2 \text { peak }}$ for fat free mass as this variable was not routineously measured in patients with CF in the CF Center at the University Medical Center Utrecht. Finally, the used criteria for a maximal effort are subject to debate, especially in patients with CF. It has previously been demonstrated that traditional testing protocols and verification criteria significantly underestimate $\mathrm{VO}_{2 \text { peak }}$ in both healthy (Barker et al. 2011) and children with CF (Saynor et al. 2013). We did not verify the attainment of a true $\mathrm{VO}_{2 \text { peak }}$ with a supramaximal exercise testing procedure.

\section{Implications and future research}

As a higher ventilatory demand seems to be present during submaximal exercise in mild-moderate patients with $\mathrm{CF}$, a small decline in ventilatory capacity might hamper the precarious balance between ventilation and homeostasis with further disease progression in patients with CF. The main findings presented in this study highlight the importance for the clinician to aim for attenuation of lung function decline even in patients with $\mathrm{CF}$ with a relatively preserved lung function ("normal" $\mathrm{FEV}_{1}$ ). For future research it would be interesting to evaluate the latter hypothesis in patients with CF with more severe airway obstruction. Moreover, the differences we found during the course of sub-maximal exercise highlight the importance to evaluate the submaximal exercise response as well when interpreting a CPET, and not just focus on peak exercise parameters.

\section{Conclusions}

The current study found an exaggerated, but adequate ventilatory response to exercise for $\mathrm{CO}_{2}$ exhalation in patients with $\mathrm{CF}$ with mild-to-moderate airway obstruction. The higher RER, VE/WR ratios, and $\mathrm{VE} / \mathrm{VO}_{2}$-slope values during sub-maximal exercise point towards a higher ventilatory demand during sub-maximal exercise in patients with $\mathrm{CF}$ and mild-to-moderate lung disease.

\section{Abbreviations}

BMl: Body mass index; BSA: Body surface area; CF: Cystic fibrosis; $\mathrm{CO}_{2}$ : Carbon dioxide; CPET: Cardiopulmonary exercise test; $\mathrm{FEV}_{1}$ : Forced expiratory volume in one second; $\mathrm{HR}$ : Heart rate; $\mathrm{HR}_{\text {peak: }}$ : peak heart rate; $\mathrm{P}_{\mathrm{ET}} \mathrm{CO}_{2}$ : Partial end-tidal carbon dioxide tension; RER: Respiratory exchange ratio; $R_{\text {ER }}$ peak: Respiratory exchange ratio at peak exercise; RV: Residual volume; RV/TLC ratio: Residual volume to total lung capacity ratio; SD: Standard deviation; TLC: Total lung capacity; $\mathrm{VCO}_{2}$ : Carbon dioxide production; $\mathrm{VCO}_{2 \text { peak: }}$ Peak carbon dioxide production; VD/NT ratio: Ventilatory dead space ventilation ratio; VE: minute ventilation; $V E_{\text {peak }}$ : peak minute ventilation; $V \mathrm{~V} \mathrm{VO}_{2}$-slope: minute ventilation to oxygen uptake slope; $\mathrm{VENCO} 2$ ratio: minute ventilation to carbon dioxide production ratio; $\mathrm{VEN} \mathrm{NCO}_{2}$-slope: minute ventilation to carbon dioxide production slope; VE/WR: minute ventilation to work rate ratio; $\mathrm{VO}_{2}$ : Oxygen uptake; $\mathrm{VO}_{2 \text { peak: }}$ peak oxygen uptake; WR: Work rate; WR: peak work rate.

\section{Competing interests}

The authors declare that they have no competing interests.

\section{Authors' contributions}

BB participated in the design of the study, carried out data analysis and drafted the manuscript. MW carried out data analysis and drafted the manuscript. TT and EH participated in the design of the study and helped to draft the manuscript. All authors read and approved the final manuscript.

\section{Acknowledgements}

Dr. Bongers and Dr. Werkman were supported by unconditional research grants from the Educational Foundation of the University Medical Center Utrecht (BB) and the Scientific Committee Physiotherapy of the Royal Dutch Society for Physiotherapy (MW).

\section{Author details}

'Department of Epidemiology, School for Public Health and Primary Care (CAPHRI), Maastricht University, Maastricht, The Netherlands. ${ }^{2}$ Child Development \& Exercise Center, Wilhelmina Children's Hospital, University Medical Center Utrecht, Utrecht, The Netherlands. ${ }^{3}$ De Kinderkliniek, Almere, The Netherlands.

Received: 14 October 2014 Accepted: 14 November 2014 Published: 27 November 2014

\section{References}

Almajed A, Lands LC (2012) The evolution of exercise capacity and its limiting factors in cystic fibrosis. Paediatr Respir Rev 13:195-199

American Thoracic Society, American College of Chest Physicians (2003) ATS/ ACCP statement on cardiopulmonary exercise testing. Am J Respir Crit Care Med 167:211-277

Armstrong N, Welsman JR (2008) Aerobic fitness. In: Armstrong N, van Mechelen W (ed) Paediatric Exercise Science and Medicine. Oxford University Press, Oxford, p 101

Barker AR, Williams CA, Jones AM, Armstrong N (2011) Establishing maxima oxygen uptake in young people during a ramp cycle test to exhaustion. Br J Sports Med 45:498-503

Beaver WL, Wasserman K, Whipp BJ (1986) A new method for detecting the anaerobic threshold by gas exchange. J Appl Physiol 60:2020-2027

Bongers BC, Hulzebos HJ, Arets HGM, Takken T (2012) Validity of the oxygen uptake efficiency slope in children with cystic fibrosis and mild-to-moderate airflow obstruction. Pediatr Exerc Sci 24:129-141

Borel B, Leclair E, Thevenet D, Beghin L, Gottrand F, Fabre C (2014) Mechanical ventilatory constraints during incremental exercise in healthy and cystic fibrosis children. Pediatr Pulmonol 49:221-229

Cerny FJ, Pullano TP, Cropp GJ (1982) Cardiorespiratory adaptations to exercise in cystic fibrosis. Am Rev Respir Dis 126:217-220

Coates AL, Canny G, Zinman R, Grisdale R, Desmond K, Roumeliotis D, Levison H (1988) The effects of chronic airflow limitation, increased dead space, and the pattern of ventilation on gas exchange during maximal exercise in advanced cystic fibrosis. Am Rev Respir Dis 138:1524-1531 
de Meer K, Jeneson JA, Gulmans VA, van der Laag J, Berger R (1995) Efficiency of oxidative work performance of skeletal-muscle in patients with cystic-fibrosis. Thorax 50:980-983

Dodd JD, Barry SC, Gallagher CG (2006) Respiratory factors do not limit maximal symptom-limited exercise in patients with mild cystic fibrosis lung disease. Respir Physiol Neurobiol 152:176-185

Eid N, Yandell B, Howell L, Eddy M, Sheikh S (2000) Can peak expiratory flow predict airflow obstruction in children with asthma? Pediatrics 105:354-358

Fredriks AM, van Buuren S, Wit JM, Verloove-Vanhorick SP (2000) Body index measurements in 1996-7 compared with 1980. Arch Dis Child 82:107-112

Godfrey S (1974) Exercise testing in children: applications in health and disease. W.B. Saunders Company Ltd, London

Green DM, McDougal KE, Blackman SM, Sosnay PR, Henderson LB, Naughton KM, Collaco JM, Cutting GR (2010) Mutations that permit residual CFTR function delay acquisition of multiple respiratory pathogens in CF patients. Respir Res $11: 140$

Hart N, Polkey MI, Clément A, Boulé M, Moxham J, Lofaso F, Fauroux B (2002) Changes in pulmonary mechanics with increasing disease severity in children and young adults with cystic fibrosis. Am J Respir Crit Care Med 166:61-66

Haycock GB, Schwartz GJ, Wisotsky DH (1978) Geometric method for measuring body surface area: a height-weight formula validated in infants, children, and adults. J Pediatr 93:62-66

Hebestreit H, Hebestreit A, Trusen A, Hughson RL (2005) Oxygen uptake kinetics are slowed in cystic fibrosis. Med Sci Sports Exerc 37:10-17

Heinicke K, Taivassalo T, Wyrick P, Wood H, Babb TG, Haller RG (2011) Exertional dyspnea in mitochondrial myopathy: clinical features and physiological mechanisms. Am J Physiol Regul Integr Comp Physiol 301:R873-884

Hjeltnes N, Stanghelle JK, Skyberg D (1984) Pulmonary function and oxygen uptake during exercise in 16 year old boys with cystic fibrosis. Acta Paediatr Scand 73:548-553

Keochkerian D, Chlif M, Delanaud S, Gauthier R, Maingourd Y, Ahmaidi S (2005) Timing and driving components of the breathing strategy in children with cystic fibrosis during exercise. Pediatr Pulmonol 40:449-56

Keochkerian D, Chlif M, Delanaud S, Gauthier R, Maingourd Y, Ahmaidi S (2008) Breathing pattern adopted by children with cystic fibrosis with mild to moderate pulmonary impairment during exercise. Respiration 75:170-177

Kusenbach G, Wieching R, Barker M, Hoffmann U, Essfeld D (1999) Effects of hyperoxia on oxygen uptake kinetics in cystic fibrosis patients as determined by pseudo-random binary sequence exercise. Eur J Appl Physiol Occup Physiol 79:192-196

Lee TW, Brownlee KG, Conway SP, Denton M, Littlewood JM (2003) Evaluation of a new definition for chronic Pseudomonas aeruginosa infection in cystic fibrosis patients. J Cyst Fibros 2:29-34

Massin MM, Leclercq-Foucart J, Sacre JP (2000) Gas exchange and heart rate kinetics during binary sequence exercise in cystic fibrosis. Med Sci Monit 6:55-62

Moorcroft AJ, Dodd ME, Morris J, Webb AK (2005) Symptoms, lactate and exercise limitation at peak cycle ergometry in adults with cystic fibrosis. Eur Respir J 25:1050-1056

Moser C, Tirakitsoontorn P, Nussbaum E, Newcomb R, Cooper DM (2000) Muscle size and cardiorespiratory response to exercise in cystic fibrosis. Am J Respir Crit Care Med 162:1823-1827

Nguyen T, Obeid J, Baker JM, Takken T, Pedder L, Parise G, Timmons BW (2014) Reduced fat oxidation rates during submaximal exercise in boys with cystic fibrosis. J Cyst Fibros 13:92-98

Ohuchi H, Nakajima T, Kawade M, Matsuda M, Kamiya T (1996) Measurement and validity of the ventilatory threshold in patients with congenital heart disease. Pediatr Cardiol 17:7-14

Pastré J, Prévotat A, Tardif C, Langlois C, Duhamel A, Wallaert B (2014) Determinants of exercise capacity in cystic fibrosis patients with mild-to-moderate lung disease. BMC Pulm Med 14:74

Pouliou E, Nanas S, Papamichalopoulos A, Kyprianou T, Perpati G, Mavrou I, Roussos C (2001) Prolonged oxygen kinetics during early recovery from maximal exercise in adult patients with cystic fibrosis. Chest 119:1073-1078

Rand S, Prasad SA (2012) Exercise as part of a cystic fibrosis therapeutic routine. Expert Rev Respir Med 6:341-351

Regnis JA, Donnelly PM, Robinson M, Alison JA, Bye PT (1996) Ventilatory mechanics at rest and during exercise in patients with cystic fibrosis. Am J Respir Crit Care Med 154:1418-1425

Saynor ZL, Barker AR, Oades PJ, Williams CA (2013) A protocol to determine valid VO2max in young cystic fibrosis patients. J Sci Med Sport 16:539-544
Saynor ZL, Barker AR, Oades PJ, Williams CA (2014) Impaired aerobic function in young cystic fibrosis patients during ramp exercise. Med Sci Sports Exerc. Epub ahead of print

Selvadurai HC, McKay KO, Blimkie CJ, Cooper PJ, Mellis CM, Van Asperen PP (2002) The relationship between genotype and exercise tolerance in children with cystic fibrosis. Am J Respir Crit Care Med 165:762-765

Selvadurai HC, Allen J, Sachinwalla T, Macauley J, Blimkie CJ, Van Asperen PP (2003) Muscle function and resting energy expenditure in female athletes with cystic fibrosis. Am J Respir Crit Care Med 168:1476-1480

Shah AR, Gozal D, Keens TG (1998) Determinants of aerobic and anaerobic exercise performance in cystic fibrosis. Am J Respir Crit Care Med 157:1145-1150

Sovtic AD, Minic PB, Kosutic J, Markovic-Sovtic GP, Gajic MB (2013) Static hyperinflation is associated with decreased peak exercise performance in children with cystic fibrosis. Respir Care 58:291-297

Stevens D, Oades PJ, Armstrong N, Williams CA (2009) Early oxygen uptake recovery following exercise testing in children with chronic chest diseases. Pediatr Pulmonol 44:480-488

Thin AG, Dodd JD, Gallagher CG, Fitzgerald MX, Mcloughlin P (2004) Effect of respiratory rate on airway deadspace ventilation during exercise in cystic fibrosis. Respir Med 98:1063-1070

Wasserman K, Zhang YY, Riley MS (1996) Ventilation during exercise in chronic heart failure. Basic Res Cardiol 91(Suppl. 1):1-11

Wasserman K, Hansen JE, Sue DY, Stringer WW, Whipp BJ (2005) Principles of exercise testing and interpretation: including pathophysiology and clinical applications. Lippincott Williams \& Wilkins, Philadelphia

Werkman MS, Hulzebos HJ, Arets HG, van der Net J, Helders PJ, Takken T (2010) Is static hyperinflation a limiting factor during exercise in adolescents with cystic fibrosis? Pediatr Pulmonol 46:119-124

Wideman L, Baker CF, Brown PK, Consitt LA, Ambrosius WT, Schechter MS (2009) Substrate utilization during and after exercise in mild cystic fibrosis. Med Sci Sports Exerc 41:270-278

Wilkens H, Weingard B, Lo Mauro A, Schena E, Pedotti A, Sybrecht GW, Aliverti A (2010) Breathing pattern and chest wall volumes during exercise in patients with cystic fibrosis, pulmonary fibrosis and COPD before and after lung transplantation. Thorax 65:808-814

Zapletal A, Samenek M, Paul T (1987) Lung function in children and adolescents: methods, reference values. In: Herzog H (ed) Progress in respiration research. Karger, Basel, pp 114-218

doi:10.1186/2193-1801-3-696

Cite this article as: Bongers et al:: Ventilatory response to exercise in adolescents with cystic fibrosis and mild-to-moderate airway obstruction. SpringerPlus 2014 3:696.

\section{Submit your manuscript to a SpringerOpen ${ }^{\circ}$ journal and benefit from:}

- Convenient online submission

- Rigorous peer review

- Immediate publication on acceptance

- Open access: articles freely available online

- High visibility within the field

- Retaining the copyright to your article

Submit your next manuscript at $>$ springeropen.com 